\title{
التوجهات التجديدية لصغار الزراع فى بعض قرى محافظة المنوفية
}

\author{
درية محمد خيرى ، أحمد الهنيدى رضوان ، عصام سيد أحمد شاهين ، امل يس محمود محمد \\ قسم الإرشاد الزراعى والمجتمع الريفى - كلية الزراعة جامعة المنوفية
}

Received: Dec. 14, 2016

Accepted: Dec. 26, 2016

الملخص

استهفت الدراسة التعرف على خصائص الزراع الاقتصادية والاجتماعية والاتصالية، والتعرف على مستوى تبنى الدزارعين للتوصيات لدحاصيل الآتية (القهح - الذرة - البطاطس - الفاصوليا) - تحديد اتجاهات النزاع نحو هذه التوصيات

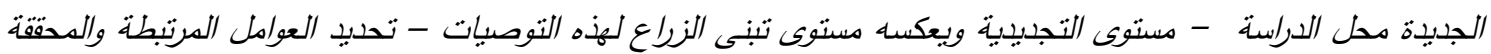
للاتجاهات التجديدية. وقد تم جمع البيانات خلال شهر فبراير وماس 2016 من قرية الخضرة وبى العرب مركز الباجور وقرية كفر عون وقرية كفر منصور مركز أشهون. وذلك باستخدام الاستبيان بالدقابلة الشخصية لعينة عشوائية منتظدة قوامها

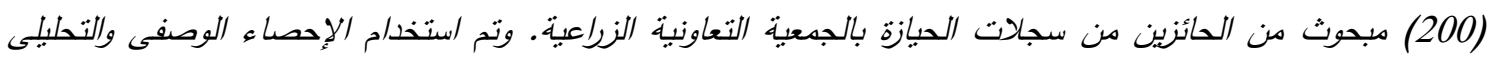
لتحليل البيانات.

وقد تم الحصول على النتائج الآتية

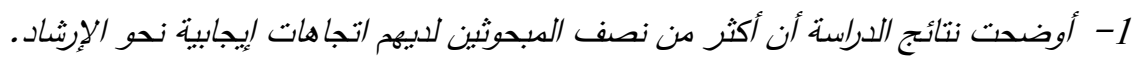
2- أظهرت النتائج أن 60\% من المبحوثين لليهم اتجاه نحو التجديبية وطرق الزراعة لتحسين العملية الإنتاجية.

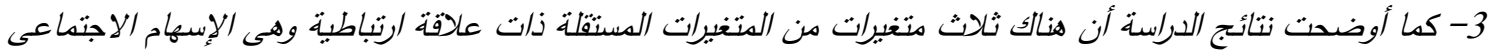

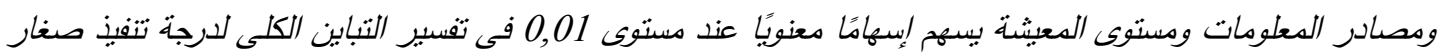

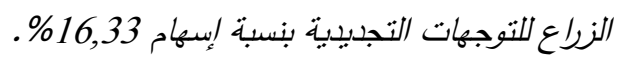

4- كما تبين من النتائج أن هناك ثلاث متغيرات قد أسهوت معنويًا في تفسير التباين الكلى للاتجاهات التهات التجديدية لصنار

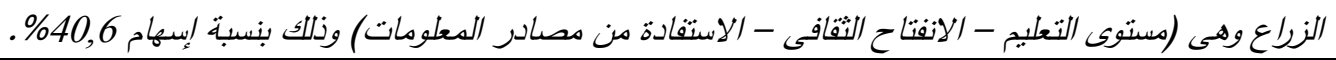

وإكساب معارف ومهارات جديدة تغير سلوكه بما ينقق مع

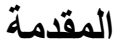

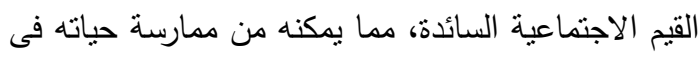
يعتبر وعى الزراع بالمبتكرات الزراعية وإدراكه

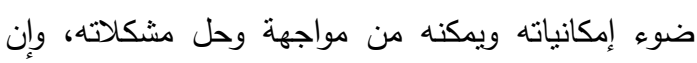
لأهميتها وفوائدها له عظيم الأثر فى تبنى تلك المبتكرات للمعرفة أثرها الواضح على عملية التننى، فالمعلومات العلمية ضرورية فى الاستخدام المناسب للمستحدثات

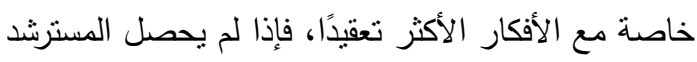
على قدر مناسب منها قبل التجريب والتبنى فإن هناك ميلاً

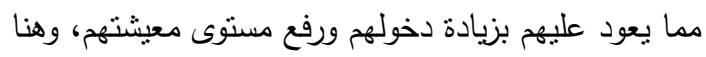
يأتى دور الجهاز الإرشادى والإعلام الزراعى بأشكاله المختلفة فى نشر تلك المبنكرات والترويج لها بين جماهير

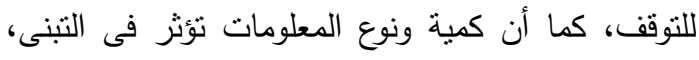
ويذكر عازر (2004) أن البنيان المعرفى للزراع يعد وإن الاستعداد لقبول التغيير والمستحدثات وعلاج

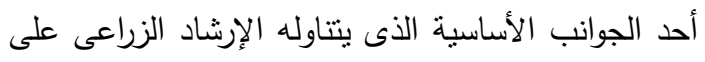

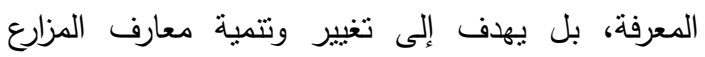


يجب أن توجه لمقابلة احتياجاتهم، حيث تبدأ بتحديد مسنوى جماهير الزراع أو القدرة على تتفيذ الممارسات

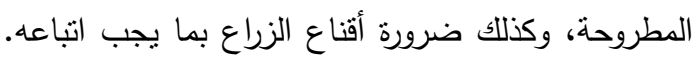

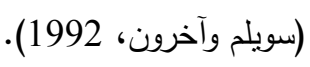

ويذكر صالح (1989) أن مجال تنبى المبتكرات

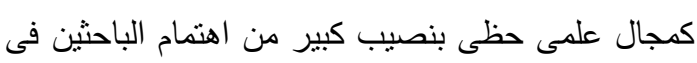

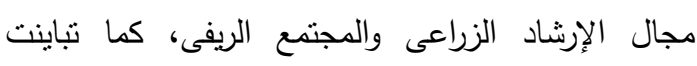

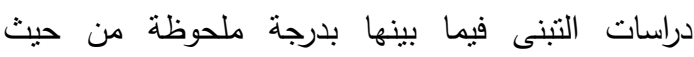

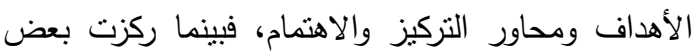
الدراسات أساسًا على عملية التبنى ومراحلها المختلفة، وتحديد المصادر المعرفية التى يلجأ إليها الزراع خلال

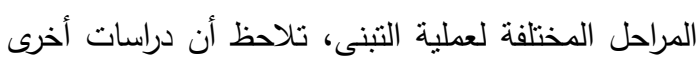

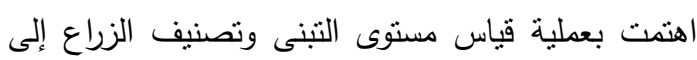

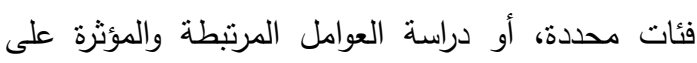

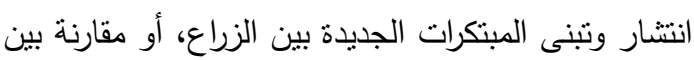

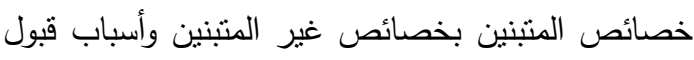

$$
\text { أو رفض المبتكرات التكنولوجية. }
$$

\section{المشكلة البحثية:}

يشكل القطاع الزراعى عصب الاقتصاد القومى

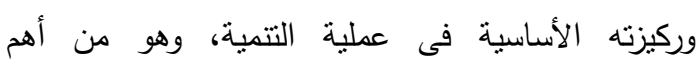

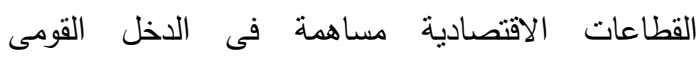
بالإضافة لكونه مصدرًا أساسيًا للغذاء ومساهمة بنسبة الفأية

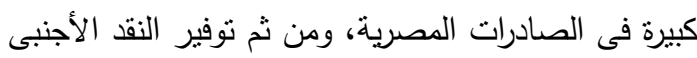
اللازم لتتفيذ خطط التتمية الاقتصادية والاجتماعية.

وكانت الحاجة لتحقيق نتمية زراعية على مستوى القاعدة العريضة من الزراع نستزم النظر بطريقة أكثر

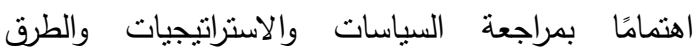
الإرشادية، بما يجعلها تتلائم مع ظروف صغار الزراع الذين يشكلون الأغلبية فى الهجتمعات الريفية المحلية، وقد أكدت نتائج البحوث الدولية والمحلية أن نسبة السكان الريفيين الذين تندنى نسبة دخولهم واستهلاكهم عن حد الفقر المحد دوليًا تبلغ فى شمال إفريقيا حوالى 26\% من
المشكلات التى تواجه المسترشدين يتوقف على المعرفة الكاملة المرتبطة بهذه المجالات. ويذكر عبد المقصود (1988) أن مستوى المعرفة يعتبر من العوامل الهامة المؤثرة فى عملية الاتصال

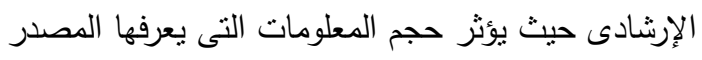

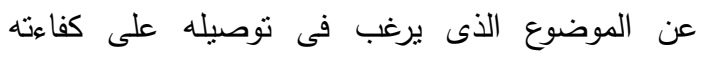
الاتصالية، فالإنسان لا يستطيع نوصيل شئ لا يعرفه أو لو لا يعرف محتوياته. ويرى المليجى ورافع (1998) أن العقل البشرى هو الأساس الذى عن طريق تطوره وحريته فى الفكر تتطور بيئته وتزدهر ، ويعم فيها الرخاء، ويعتد هذا الرأى أساسًا

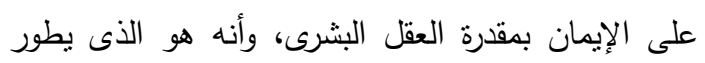
سلوكه ويطور بيئته بما يتتاسب مع ما براه لإنئن صالحًا

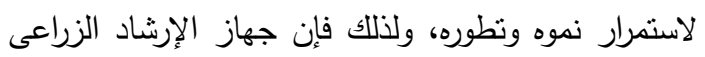
يوجه جهوده فى هذا الصدد للمجتمع الريفى باعتباره

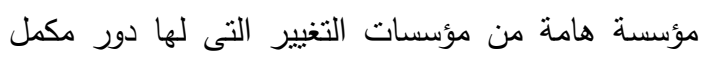

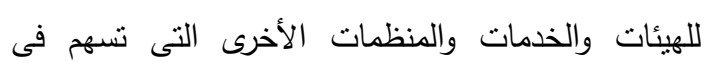
تتميتهم وليس منافيًا لها، وذلك بإحداث التغييرات السلوكية التهات المرغوبة لدى الزراع وفقًا لثلاثة أنواع:أ- إحداث تغييرات فى السلوك التفكيرى أو المعرفى ابتداءً من إضافة معلومة حتى التغييرات الثاملة فى البنيان

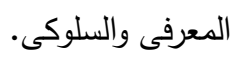

ب- إحداث تغييرات فى السلوك الشعورى أو الاتجاهى ويتعلق هذا النوع بشعور المسترشد نحو التقنيات الحديثة ونوع الاستجابة لها.

ج- إحداث تغييرات فى السلوك التتفيذى أو المهارى أو

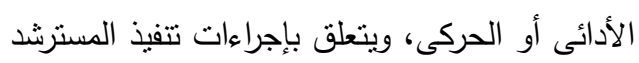
لما يتعلمه من تقنيات ومستحدثات زراعية وكيفية تطبيقها بصورة آمنة. وحتى يتمكن جهاز الإرشاد من إحداث التغييرات المرغوبة فى مستوى معارف الزراع وتتفيذهم للممارسات الفنية المستحدثة وتعديل اتجاهاتهم نحوها، فإن رسالته 


\section{Khairy, et al.,}

ومع زيادة التكنولوجيا الزراعية المتاحة فإن الفئة من صغار الزرع لا تصل إليهم تلك التكنولوجيا ولا يسنطيعون الاستفادة منها فى تحسين حياتهم.

مما يشكل عبء على عملية التتمية فى المجتمع وجود

فئة لا تصل إليها جهود التتمية التى تسعى إليها الدولة. ومن هنا سوف تقوم الدراسة بالبحث فى ددى تبنى استفادة صغار الزراع بالتكنولوجيا الحديثة والأساليب الزراعية المستحدثة لزيادة معدل الإنتاج خاصة لصغار الزراع والتعرف على اتجاهات صغار الزراع التجديدية، لرانية وكيف يمكن تحسين تللك الاتجاهات وتوجيه فئة صغار

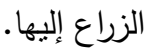

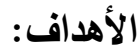

تستهدف هذه الدراسة بصفة أساسية تحديد الاتجاهات التجديدية لصغار الزراع من خلال تطبيق الأهداف الفرعية

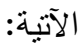

التعرف على خصائص الزراع الاقتصادية والاجتماعية

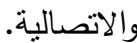

التعرف على مسنوى معرفة المزارعين للتوصيات الجديدة للمحاصيل الآتية: (القمح والذرة والفاصوليا والبطاطس) تحديد اتجاهات الزراع نحو هذه التوصيات الجديدة محل

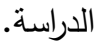

مستوى التجديدية ويعكسه مستوى تننى الزراع لهذه

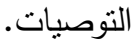

تحديد العوامل المرتبطة والمحققة للاتجاهات التجديدية.

الإطار النظرى والاستعراض المرجعى الإطار المفهومي للاراسة

1 - ملية الانتشار أو الذيوع Diffusion

\section{Process}

ويحلل Rogers (1995) عملية انتشار وذيوع المبتكرات إلي أربعة عناصر رئيسية، أول هذه العناصر

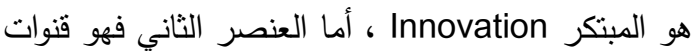

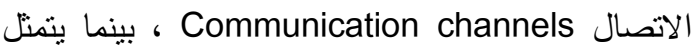

جملة السكان، منهم أكثر من 19 مليون في مصر وحدها.

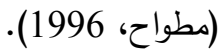
وتعاني محافظة المنوفية من ضيق مساحة الرقعة الزراعية حيث تبلغ المساحة الكلية المنزرعة بالمحافظة 288904 فدان (الثئون الزراعية، مديرية الزراعة بالمنوفية،2015) كما يبلغ إجمالي عدد السكان بها 3870439 نسمة (النتائج النهائية للتعداد العام للسكان ، لانعان محافظة المنوفية ،2015) وبالتالي يبلغ نصيب الفرد من

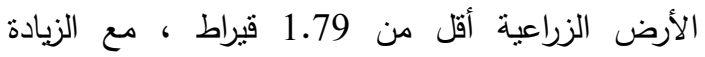
السكانية المضطردة نجد أن هناك مشكلة فى نوفير وسد الاحتياجات الغذائية، حيث لا يقابل الزيادة السكانية زيادة

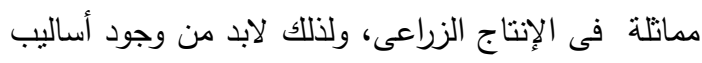
زراعية غير تقليدية جديدة لنوفير المحاصيل المختلفة والمنتجات الزراعية محليًا جنبًا إلى جنب مع النوسع راعير الأفقى والتوسع الرأسى، وضيق مساحة الرقعة الزراعية يجعل من الصعب زراعة ددى واسع ومنتوع من المحاصيل وخاصة المحاصيل الاستراتيجية الهامة مثل

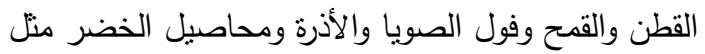

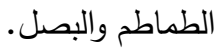
ومحافظة الدنوفية محافظة زراعية بالدرجة الأولى حيث تثتهر بزراعة الذرة الثامية والقمح والقطن والخضر

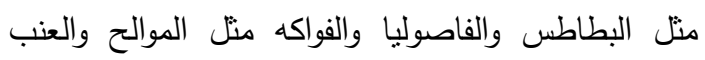
والموز، والتى يتم تصدير معظمها إلى المحافظات

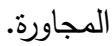

وتقدر المساحة المحصولية المنزرعة بالمنوفية لعام 2015 بمساحة 460255 فدان تقريبًا منها 7.7 المساحة المنزرعة فى الخضر وبالتالى نكن المساحة المنزرعة من الخضر بالمنوفية تقريبًا 35440 فدان وتبلغ نسبة المساحة المنزرعة من المحاصيل 31.5\% من إجمالى المساحة المنزرعة بما بعادل 144980 فدان تقريبًا.

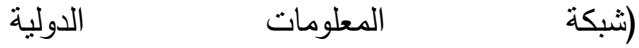

. ( www.Agricultureegypt.com/NewsDetail 
مدي زمني طويل، وعلي أساس درجة نقبل الناس للفكرة

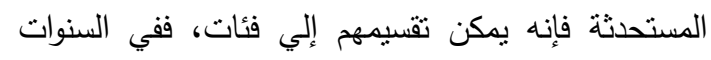

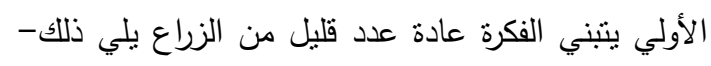

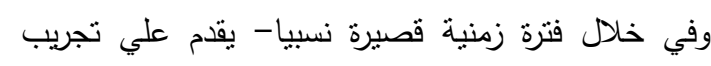

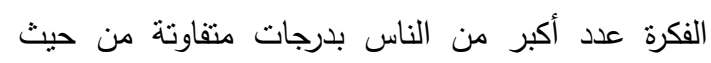

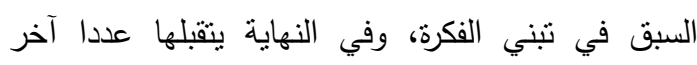
بدرجات متفاوتة أيضا وقد لا يتقبل البعض الفكرة مطلقا.

$$
\text { (العادلي، } 1972 \text { ) }
$$

$$
\text { ويثير كل من العادلي (1972) وعبد الدقصود }
$$

(1988)، وإيمان عثمان (2009 ): - نقان عن عن ليلة

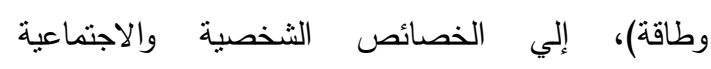

$$
\text { والاقتصادية لكل فئة من فئات المتنبنين وهي: الفئي }
$$

أ) المبتكرون Innovators وتبلغ نسبته

$$
\text { وسماتهم كما يلي: }
$$

1- - روح المغامرة والرغبة الثديدة في تجريب الجديدة

$$
\text { 2- - - - أكثر انفتاحا علي العالم الخارجي }
$$

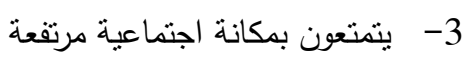

4- - يغلب عليهم التخصص في أعمالهم

5- الاتصال الوثيق بمصادر المعلومات الزراعية

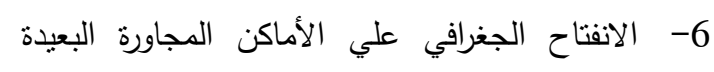

$$
\begin{aligned}
& \text { المتحضرة } \\
& \text { 7- غالبيتهم من قادة الرأي في مجتمعاتهم }
\end{aligned}
$$

ب) المتننيون الأوائل Early Adaptors وتبلغ

$$
\text { نسبتهم 13.5\% ويتميزون بالآتي: }
$$

1- يعتبرون مصدر مرجعي يرجع إليهم لطلب

$$
\text { النصح والمشورة }
$$

$$
\begin{aligned}
& \text { 2- يتمتعون بالاحترام وتقدير الآخرين } \\
& \text { 3- بمتلكون حيازة زراعية كبيرة } \\
& \text { 4- يميلون إلي التخصص في العمل } \\
& \text { 5- أكثرهم قادة محليين أو قادة رأي لي العيل }
\end{aligned}
$$

ج) الغالبية المبكرة Early Majority وتبلغ نسبتهم 34 ويتميزن بالآتي:
، Social system العنصر الثالث في النسق الاجتماعي أما العنصر الرابع فهو الزمن Time. وفي هذا الثنأن يري الني

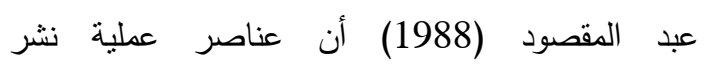
المستحدثات نطابق عناصر عملية الاتصال فالمستقبلون

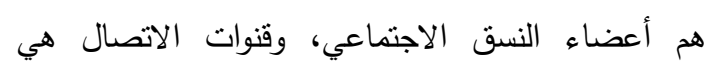
الوسائل التي يتم بواسطتها انتشار ونقل الفكرة الجديدة،

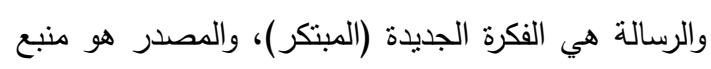

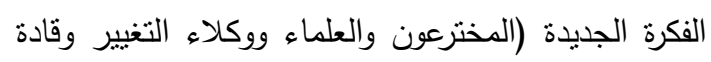
الرأي وما شابه ذلك)، والاستجابة أو الآثار هي التغييرات في معلومات واتجاهات وسلوك الأفراد حول تلك الفكرة.

أولا : الابتكارية وفئات المتبنيين تعني ابتكارية الفرد- أو أي وحدة تبني أخري- السبق الانئن النسبي في تبني مبتكر معين مقارنة ببقية أفراد النظام

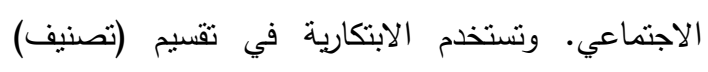

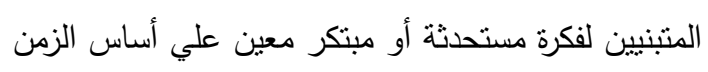
الذي تم فيه تبني تلك الفكرة إلي مجاميع أو فئات بطلق التئن

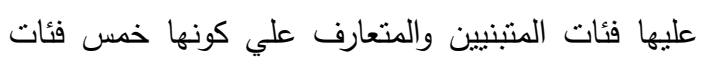

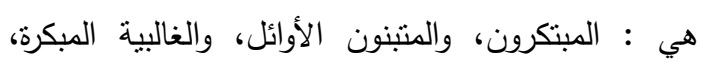

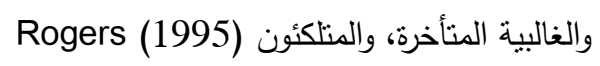
ويري سلامة (2001) أن درجة ابتكارية الفرد نتوقف علي وصائصه النفسية والثخصية والاجتماعية

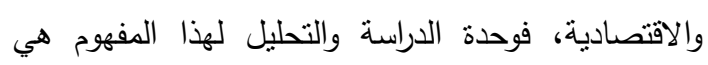
الفرد، بينما يركز مفهوم معدل التبني علي المبتكر نفسه كوحدة دراسة علي أساس تباين الممارسات الزراعية

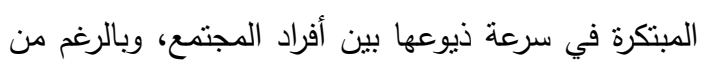
أهمية التمييز بين الدفهومين السابقين إلا أن الدراسات

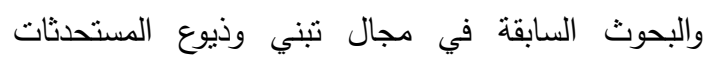
الزراعية قامت بتحليل سلوك الأفراد تحت مسميات: مستوي التنبي، معدل التبني، درجة التبني، مدي التنبني. فن الواضح أن جميع الزراع لا يتبنون الفكرة الجديدة

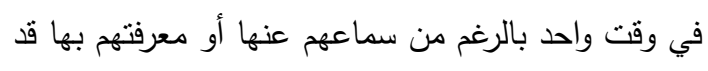

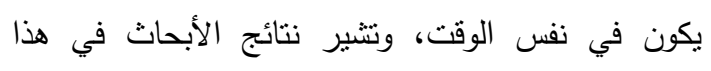
المجال أن ذيوع وتبني أي فكرة مستحدثة يتطلب في العادة 


\section{Khairy, et al.,}

وتتشير نتائج البحوث إلي أن المزارعين يتبنون المبنكرات الزراعية في أوقات متباينة كما أن تبني المبتكر البرات يحدث أولا بين مجموعة قليلة من المزارعين ثم عدد أكبر حتي يتقبلها الباقون. ويوضح الثكل رقم (1) تقسيم فئات التنبي علي أساس الزمن الذي تم فيه تنبي الفكرة

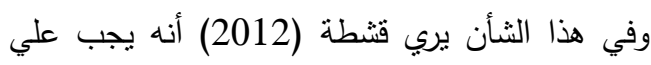
الإرشاد الزراعي الاهتمام بفئات تبني الزراع للمستحدثات

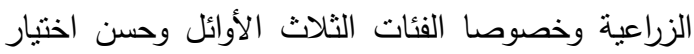
الأساليب والطرق الإرشادية المناسبة لكل فئة منها، وكذلك

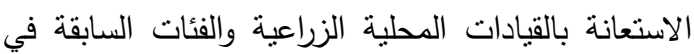
التعامل مع الفئة الرابعة لإقناعها بالمستحدثات الزراعية وسرعة استجابتها، أما الفئة الأخيرة فيفضل تجنب المرشد في التعامل معها وفي حالة التعامل معها يكون بحرص الند شديد.

\section{الاتجاهات التجديدية لصغار الزراع

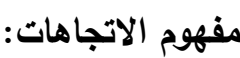

تعـددت المحسـاولات المبذولـة للوصــول إلـي مفهـوم

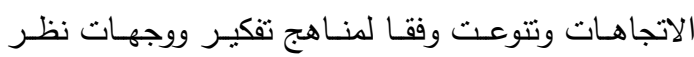
العديد من الباحثين والخبراء في مجال العلوم الاجتماعية،

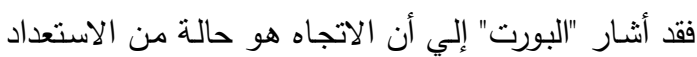

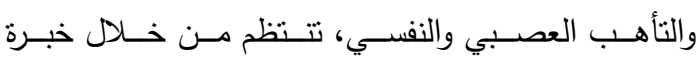
الثخص، وتكون ذات تأثثير توجيهي علي استجابة الفرد لجميع الموضوعات والمواقف التي تسنتير هذه الاستجابة. (سويف، 1970).
1- يتمتعون بالمثابرة والاستعداد لنتيني الابتكارات الجديدة بعد التأكد من نجاحها عند الآخرين

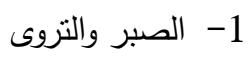
2- يتمتعون بمراكز اجتماعية هامة 3- لايهم سعة حيازية متوسطة 4- علي اتصال وثيق بوكلاء التغيير

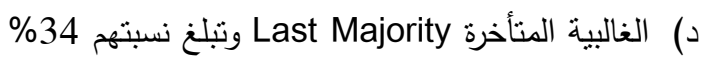
ولديهم السمات الثالية:

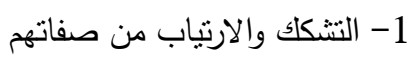

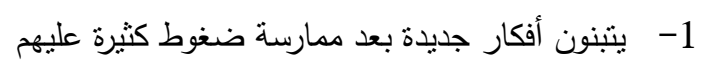
2- - بتمتعون بمكانة اجتماعية دون المتوسطة 3- - لديهم سعات حيازية محدودة

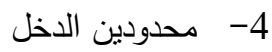
5- - بسنقون معارفهم من زراع آخرين

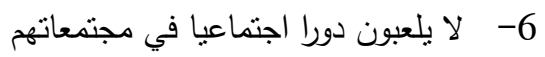

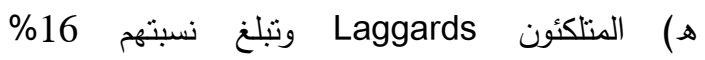
ويمتازون بالآتي: 1- التمسك بالتقاليد والقديم في جميع تصرفاتهم 2- - ذوبي مكانة اجتماعية منخفضة

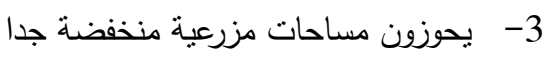
4- - ذ ذوي دخول منواضعة جدا 5- انخفاض المستوي التعليمي

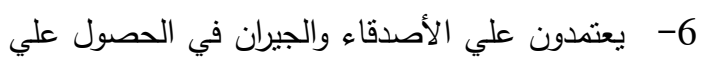
المعلومات الزراعية -7 - لا يلعبون دور قيادي محلي لمراعة

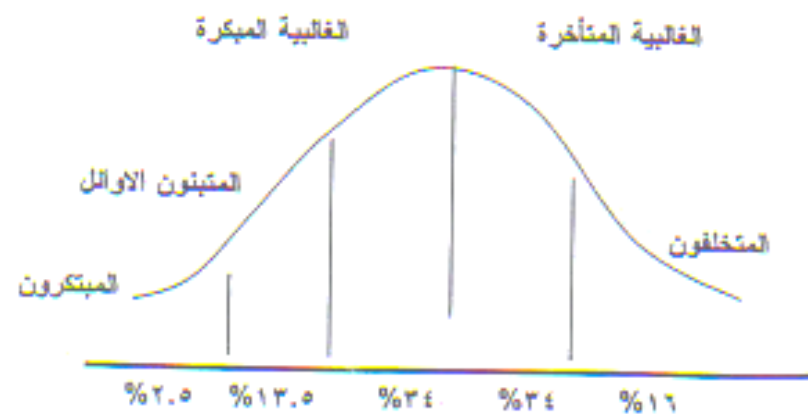

شكل رقم (1) تقسيم فئات المتبنيين علي أساس الزمن الذي تم فيه تبني الفكرة المصدر : العادلي ( 1972)، عبد المقصود ( 1988 )، وإيمان عثمان ( 2009 نقانلا عن ليلة وطاقة) 
وتتشبر الاتجاهات إلي نزعات نؤهل الفرد للاستجابة

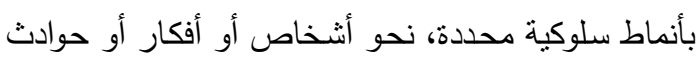

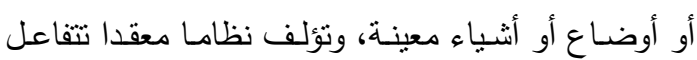
فيه مجموعة كبيرة من المتغيرات المتنوعة. وأن أية محاولة أنة

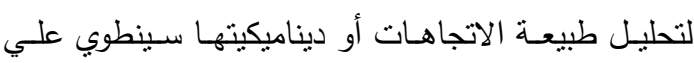

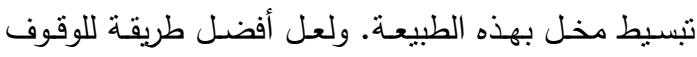

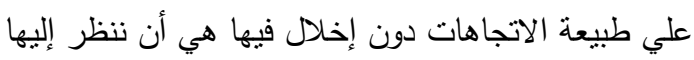

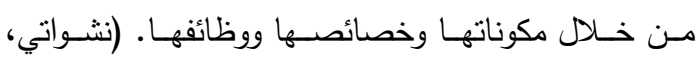

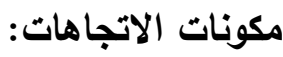

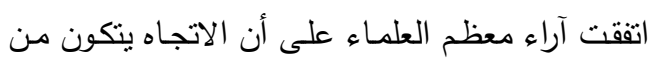

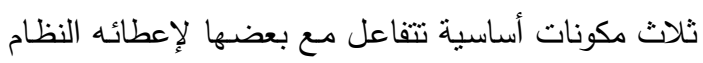
أو الثكل النهائى، وأهم المكونات هى: تلنى

$$
\text { 1- المكون المعرفى: }
$$

ويمثل معارف الثخص حول موضوع الاتجاه كالواقع، والمعرفة، والمعتقدات التى تتصل بموضوع الاتجاه. ويشـير إلـى النـواحى العاطفيـة والوجدانيـة المرتبطــة بالثئ موضوع الاتجاه، وهذا الجانب يضفى على الاتجاه طابع الدفع والتحريك.

\section{2- المكون العاطفى أو الوجدانى:}

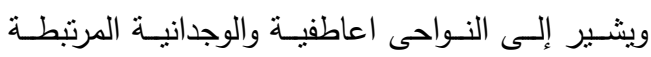
بالثئ موضوع الاتجاه، وهذا الجانب يضفى على الاتجاه طابع الدفع والتحريك.

$$
\text { 3- 3- المكون السلوكى: }
$$

ويشـير إلـي الاستعدادات السـلوكية المرتبطـة بالاتجـاه وذللك وفقا لأنماط محددة وأوضاع معينة.فإذا كان المزارع للديه اتجاه إيجابي نحو الإرشاد الزراعي، فأنه يسعي دائما

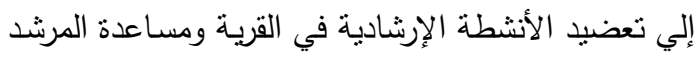

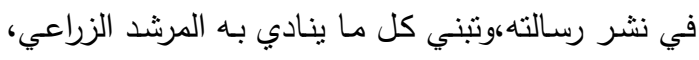

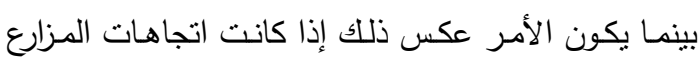

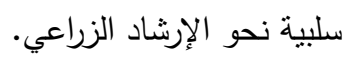

كما عرف عمر وآخرون (1976) الاتجاه بأنه ميل

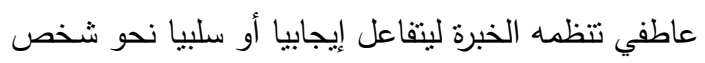

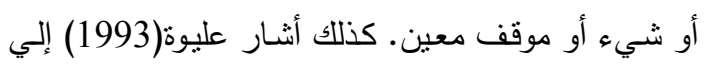
الاتجاه باعتباره حالة من الاستعداد العقلي والعاطفي الذي لئي

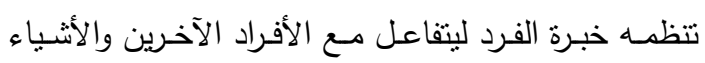

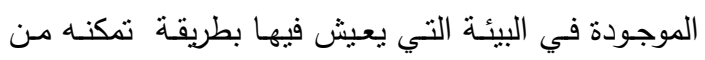

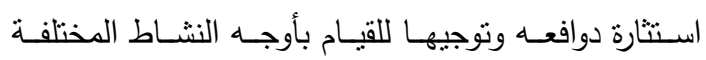

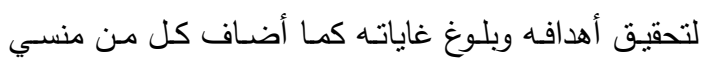
وآخرون (1994)، وسكر (1996) أن الاتجاه هو مجموعة الفان

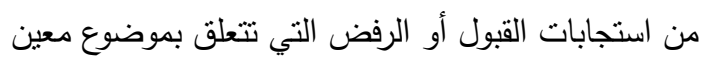

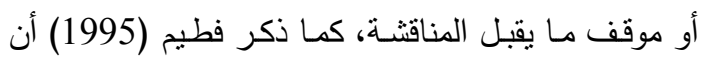

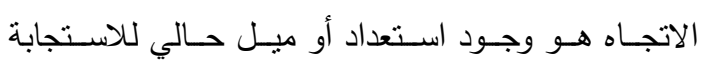
للموضوعات الاجتماعية يعمل علي توجيه السلوك الظاهر للفرد خلال المواقف بما تحتويه من متغيرات. وأضـاف النصـار وآخرون (1996) أن الاتجاه هو رد

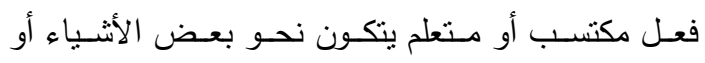

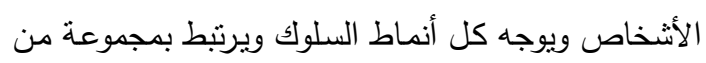

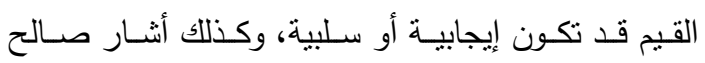
(1997) أن الاتجــاه هـو حالــة مـن الاسـتعداد العقلـي

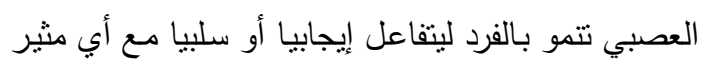

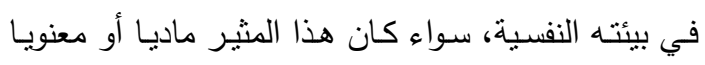
بناءا علي خبرات شخصية سابقة مباشرة أو غير مباشرة

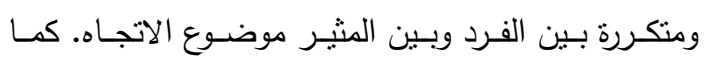

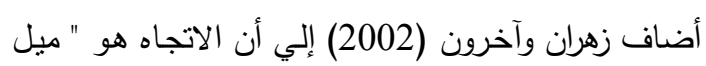

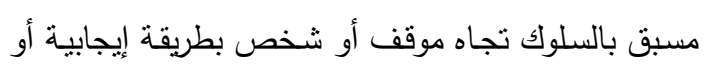
سلبية". وهكذا بعد استعراض هذا القدر اليسير من المحاولات التي تتاولت مفهوم الاتجاهات فأنه يمكن القول بأن الاتجاه

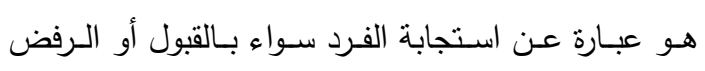
(إيجابيا أو سلبيا ) نحو مثير خارجي سواء كان هذا المثير فرد أو موضوع أو موقف معين، وتخضع هذه الاستجابة النية للعديد من العوامل التي تلعب خبرة الفرد دورا بارزا فيها. 


\section{Khairy, et al.,}

فـى حالـة مزمنـة، وعاجزون عن الوصسول إلى مؤسسـات

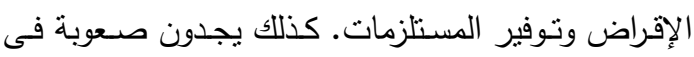

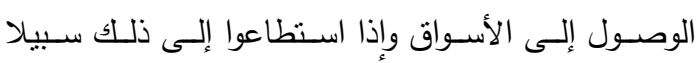

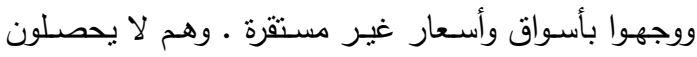

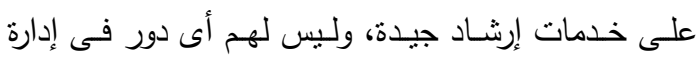

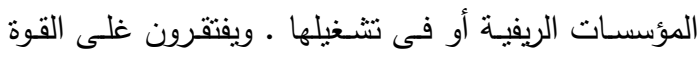

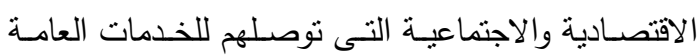

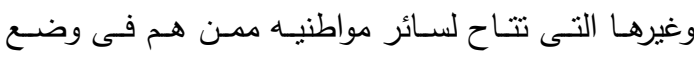

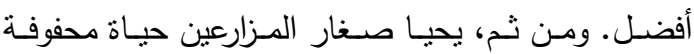
بالمخاطر حتى إن العوامل المناخية والأسعار كفيلة بأن تسبب للمزارع وأسرته كوارث حقيقية. وإن كان صغار الزراع يشتركون فى قلة الموارد وانخفاض الدخل، إلا أن أسلوب عمهم فى كافة أنحاء

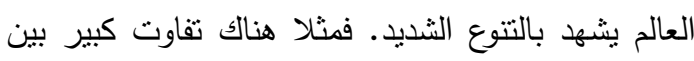
أساليب الزراعة فى المناطق الرعوية شبه الجافة فى أفريقيا

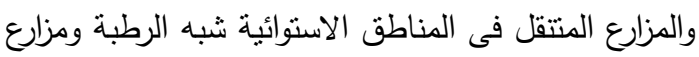
الأرز على الأمطار الموسمية فى آسيا. وبقدر ما يختلف

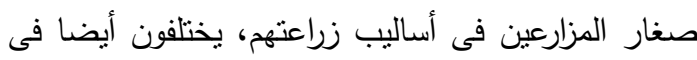

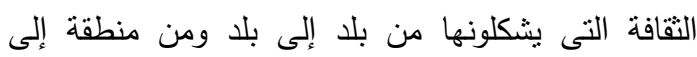

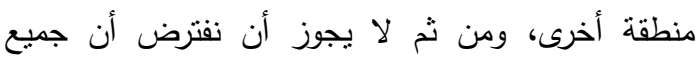
المزارعين الصغار متجانسون حتى فى داخل المنطقة الواحدة. (بحوث إدارة المزارع لتتمية صغار المزالرعين -

$$
\text { قسم الاقتصاد الزراعى وإدارة المشاريع). }
$$

الاراسات السابقة

(1) دراسة محمد (1998): بعنوان "أثر مستوى المعيثة على تجديدية الريفيات"

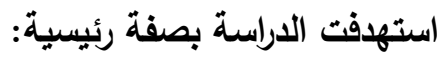

1- التعرف على درجة تحديدية الريفيات فى المراحل

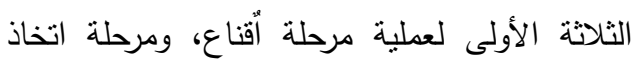
القرار ، كل على حدة، وللثلاث مراحل مجتمعة. 2- دراسة أثز مستوى معيشة الريفيات على هذه

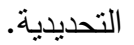
أجرى هذا البحث فى قرية جروان مركز الباجور بمحافظة المنوفية على عينة عشوائية منتظمة قوامها 150
وتتبـاين مكونـات الاتجــاه مسن حيـث درجـة قوتهـا

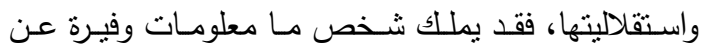
موضوع ما ( المكون المعرفي)، غير أنه لا يشعر حياله برغبة قوية (المكون العاطفي) تؤدي به إلي اتخاذ أي عمل التل

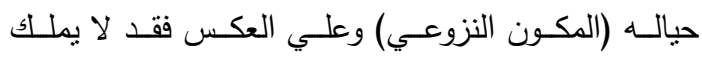
الثخص أية معلومات عن هذا الموضوع، ومع ذللك يتفاني في العمل من أجله، إذا كان يملك شعورا تقبليا قويا نحوه. (السيد وآخرون، 1987)، (درويش وآخرون، 1993)

\section{تعريف المزارع الصغير؟}

"صغار المزارعين"، ان هذا التعريف، فى سياق هذه

المناقتنـات، عبـارة عـن مفهوم واسـع تمامـا: فــالمزارع

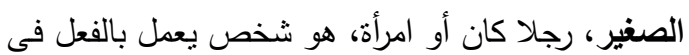

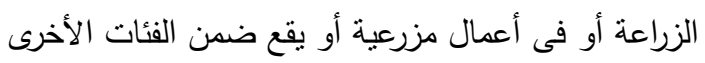
لصغار المنتجين غبر الزراعيين مثل الصيادين الحرفيين والرعاة الرحل وتجار الحيوانات الصغيرة.

"مجموعة صـفار المـزارعين "تعرّف بأنها مجموعة

غير رسمية وطوعية تعمل بالجهود الذانية تتألف من 5 الى 15 شخصا من صغار المزارعين من نفس القرية أو

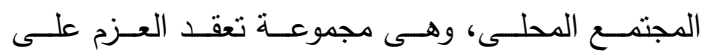
الاضطلاع بنشاطات تحقق المنفعة المنبادلة وذات صلة بتحسين مستواها الاقتصـادى والاجتمـاعى. والتلقائية هى التى السمة الهامة لهذه المجموعات: فهى مجموعات تعمل من لألى القاعدة الى القمة وليس من القمة الى القاعدة. https://www.google.com.eg/search?biw=128 $\underline{0 \& \mathrm{bih}=865 \& \mathrm{q}}$

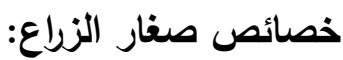

تتمثل أبرز خصـائص صــار المـزارعين فـى قاعدة الموارد الصغيرة التى عليهم تثغيلها والنى تدر عليهم دخلا منخفضـا. فهم فـى معظم الأحيـان يتحكمون فـى رقعـة صغيرة من الأرض (دون ضمان للحيازة) تكون غالبا من لان

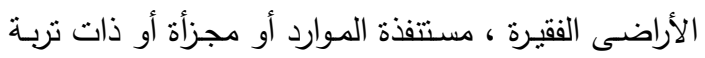
فاسـدة ، كمـا ان قدراتهم الثخصـية على العـلـ شـديدة

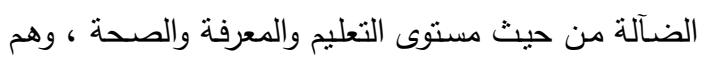


الجماهيرى، وحجم الحيازة الأرضية المزرعية،

والدخل السنوى والمشاركة وتبنى درجة النحديث

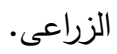

7- أظهرت النتائج البحثية أن ستة متغيرات مستقلة فقط

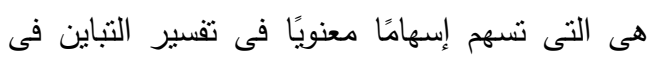
درجة التحديث الزراعى وهى المقتئيات المنزلية فئي

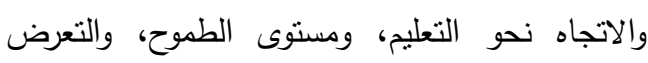

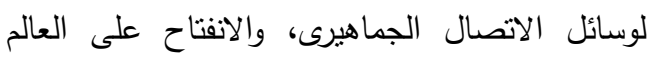

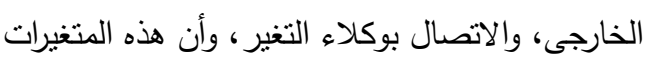

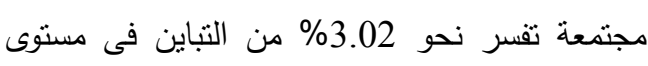
التجديد الزراعى.

(2) دراسة عبد الرحمن (1994): بعنوان "محددات

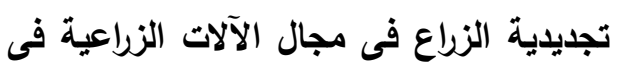

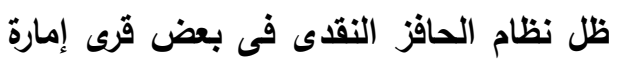
الرياض بالمملكة العربية السعودية" استهدفت الدراسة بصفة رئيسية: 1 التعرف على طبيعة الآلات الزراعية بين الزراع فى لئهئ ظل نظام الحافز النقدي 2 2 التعرف على مصادر المعلومات التى يستقى منها

$$
\text { الزراع معارفهم عن الآلات الزراعية. }
$$

3

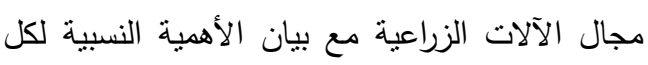

\section{منها.}

وذكر أن الكثف عن العوامل المؤدية إلى أسبقية الأفراد فى استخدام التقنيات الجديدة من شأنها إمكانية العية التئية تغيير بعض المتغيرات المرنبطة بالتجديدية بافتراض أنها

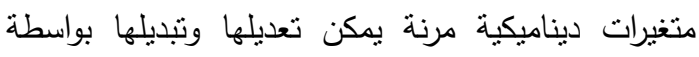

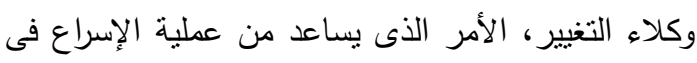

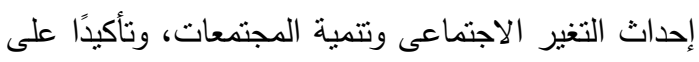

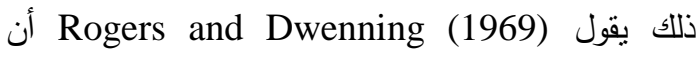
التجديدية تعد أفضل المؤشرات فى قياس التحديث.

وقد تم إجراء هذه الدراسة فى إمارة الرياض بالمنطقة الوسطى فى المملكة العربية السعودية على عينة عشوائية
مبحوث من الحائزين وزوجات الحائزين من سجلات الحيازة بالجمعية الزراعية، وقد نم جمع البيانات من خلال

الاستييان بالمقابلة الثخصية.

$$
\text { وكانت أهم التتائج البحثية ما يلى: }
$$

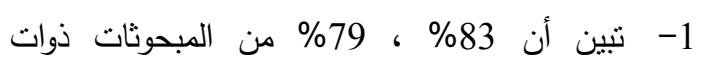

تجديدية إما منوسطة أو مرتفعة فى مرحلتى السماع

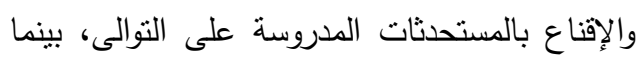

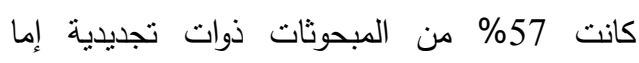
متوسطة أو مرتفعة فى مرحلة اتخاذ القرار باستخدام المستحدثات المدروسة، وأن هناك انخفاضًا متدرجًا

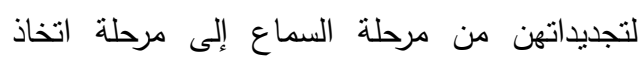
القرار •

2- أن أكثر من ثلثى المبحوثات 70,7\% ذوات تجديدية إما متوسطة أو مرتفعة بالنسبة للمراحل الثناثة

\section{مجنمعة.}

3- وجود تأثثر معنوى عند 0,05 بين مستوى معيشة المبحوثات على درجة تجديداتهن فى مرحلة الإقناع

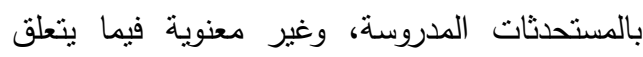
بمرحلتى السماع واتخاذ القرار باستخدام المستحدثات موضع الدراسة.

4- عدم وجود تأثير معنوى بين مستوى معيثة المبحوثات ودرجة تجديداتهن بالنسبة للمراحل الثلاثة مجتمعة. 5- أوضحت النتائج وجود علاقة موجبة معنوية بين كل من حجم حيازة الأرض الزراعية وحجم حيازة الماثشية، وجنة

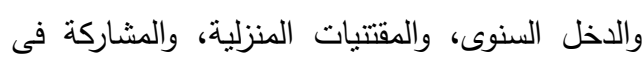
الأنشطة التتموية، وقيادة الرأى، والانفتاح على العالم الثنات

$$
\text { الخارجى، ودرجة تحديث الزراعة. }
$$

6- أوضحت النتائج وجود علاقة معنوية موجبة بين حجم حيازة الماشية، ومسنوى المعيثة والمفتنيات

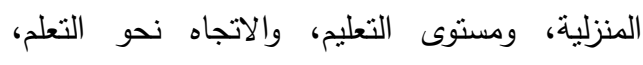

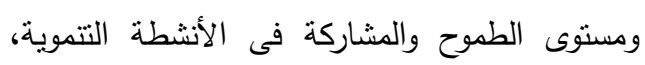

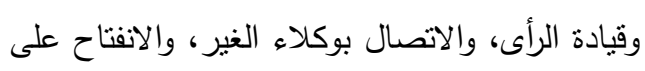

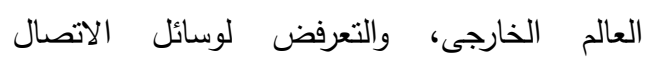




\section{Khairy, et al.,}

مجتمع الدراسة من صغار المزارعين فى المراكز التى تم تجميع البيانات لها وفقًا للحيازات الزراعية لديهم النى بلغت التارت 200 مزارع وتم تجميع البيانات منهم عن طريق المقابلة

الشخصية

$$
\begin{aligned}
& \text { 1- كفر منصور (55) مبحوث } \\
& \text { 2- كفر عون (20) مبحوث } \\
& \text { 3- - بى العرب (35) مبحوث } \\
& \text { 4- الخضرة (90) مبحوث }
\end{aligned}
$$

تم جمع البيانات الميدانية من خلال مقابلة المبحوثين والاستعانة باستمارة اسنتيان نم إعدادها وتصميمها لهذه

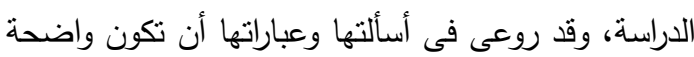

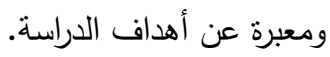

وقد تم إجراء الاختبار المبدئى لها بقرية كفر عون بمعدل 20 استمارة من غير عينة البحث، وتم تعديلها وصياغة الأسئلة حتى يمكن للمبحوث فهمها والإجابة

عليها، ومن ثم أصبحت الاستمارة فى صورتها النهائية.

\section{المتغيرات البحثية وكيفية قياسها:}

تضمنت هذه الدراسة 20 متغيرًا بحثيًا منهم 13 متغير مستقل و هى : السن - الحالة الاجتماعية - حجم الاسرة

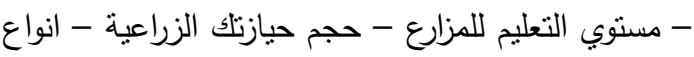

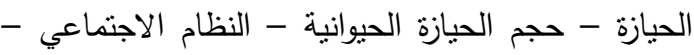
الانفتاح الجغرافي - الانفتاح الثقافي - المستوي المعيشي - الاتجاه نحو الارشاد - الاستفادة من مصادر المعلومات، و6 متغيرات تابعة، وهى : اتجاه الزراع نحو لأنواد

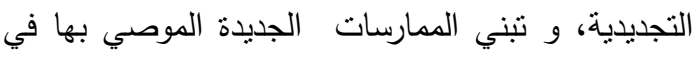
محصول القمح والأذرة والبطاطس والفاصولياء - درجة

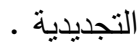

\section{التوجهات التجديدية:}

ويقصد بها سلوك تطبيق المبحوث نحو التقنية الجديدة من استخدام تقاوي عالية الانتاج في القمح والاذرة والبطاطس والفاصولياء : زراعة البطاطس بالسطارة تسوية الارض بالليزر - استخدام اسمدة ورقية - استخدام
من الزراع ييلغ قوامها 83 مزارعًا من ثلاث قرى هى:

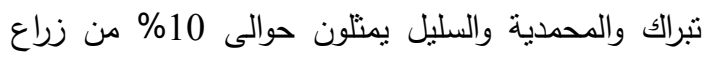
هذه القرى. وقد جمعت بيانات هذه الدراسة عن طريق المقابلة الثخصية باستخدام استمارة استبيان.

ويمكن تلخيص أهم النتائج البحثية التى توصل إليها الباحث فيما يلى: 1- أوضحت النتائج أن الزراع يعتمدون على الكثير من مصادر المعلومات لاستقاء معارفهم عن الآلات، ويتباينون فى مقدار كثافة استعمالهم لكل منها، وكان أهم هذه المصادر تجار الآلات الزراعية يتبعها الأهل والجيران والأصدقاء ثم المرشد الزراعى. 2- أوضحت النتائج أن هناك علاقة موجبة معنوية بين كل من الخبرة المزرعية وتعليم الأبناء وقيادة الرأى

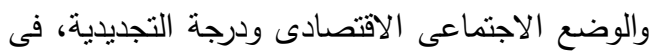

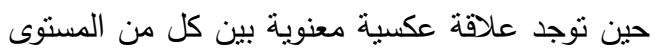

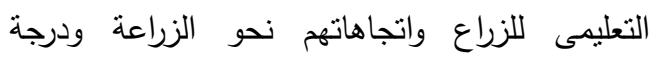
التجديدية، كما تبين عدم وجود علاقة ذات دلالة إحصائية بين كل من عمر المزارع وحيازته المزرعية،

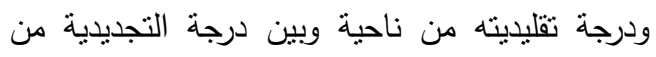

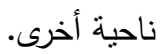

\section{الإجراءات البحثية}

وقد اختير مركز أثنمون ومركز الباجور لإجراء هذه الدراسة باعتبارهما من أكير مراكز المحافظة اهتمامًا بزراعة الخضر والمحاصيل، وتم اختيار قريتى كفر عون وكفر منصور من مركز أشمون وقرينى بى العرب والخضرة من مركز الباجور؛ وذلك لانتشار زراعة

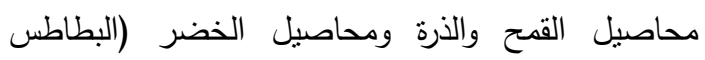
والفاصوليا) بهما مقارنة بباقى المحاصيل بالإضافة إلى الى

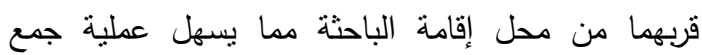
البيانات ويوفر الوقت والجهـ اللازمين لذلك. بدأت الدراسة

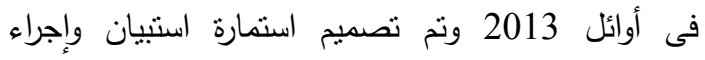
الاختبار المبدئى خلال عام 2015 ثم جمع البيانات خلال الفترة من شهر فبراير 2016 إلى شهر مارس 2016.تمتل 
التدريجى الصاعد وأظهرت نتائج التحليل الإحصائى باستخدام معامل الارتباط البسيط الموضحة بالجدول رقم (1 ) أن هناك علاقة ارتباطية موجبة معنوية على مستوى بلإمل 0.01 من درجة تنفيذ الزراع للاتجاهات التجديدية التئية

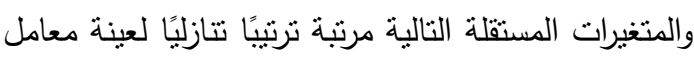
الارنباط البسيط .

مصادر المعلومات 0.610 ، الانفتاح الثقافى 0.598

ومسنوى التعليم 0.446 والإسهام الاجتماعى 0.234 والانفتاح الجغرافى 0.223

وقد تبين أيضًا من النتائج أن درجة تنفيذ الزراع للاتجاهات التجديدية كانت ذات علاقة "ارتباطية" معنوية

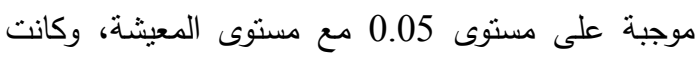
قيمة الارتباط 0.210 حجم الحيازة، وكانت قيمة معامل الارتباط البسيط 0.104

وتثير النتائج إلى أن الاتجاهات التجديدية نزيد بزيادة كل من المتغيرات المستقلة السابقة والعكس صحيح. بينما اتضح من النتائج عدم وجود علاقة ارتباطية معنوية فى أى اتجاه على مسنوى 0.05 بين الدرجات المعبرة عن درجة تنفيذ الزراع الاتجاهات التجديدية وبين التئن

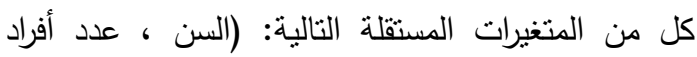
الأسرة، مستوى التعليم ، حجم الحيازة، الحيازة الحيوانية،

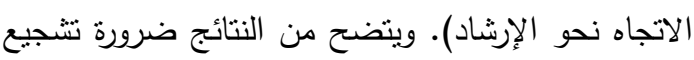

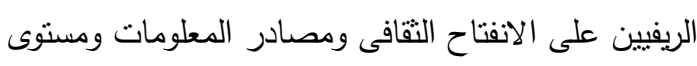

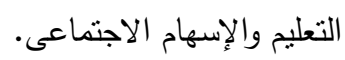

وقد اتضح من النتائج الواردة بالجدول رقم (2) أن هناك ثلاثة متغيرات فقط قد أسهوت معنويًا فى تفسير

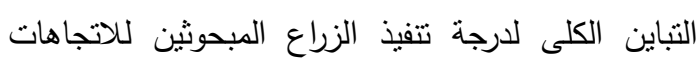

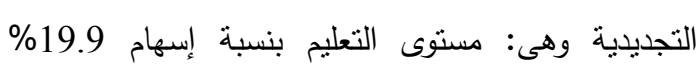

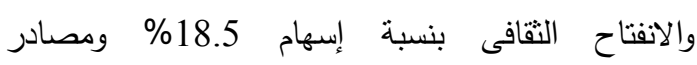

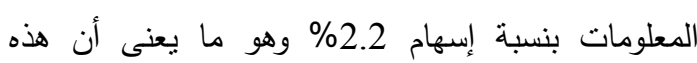
المتغيرات معًا تفسر 40.6\% من التباين فى الدرجات بعات المعبرة عن تتفيذ الزراع المبحوثين للاتجاهات التجديدية

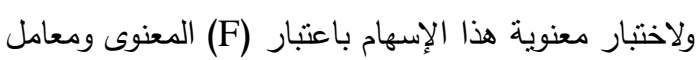

عناصر صغير - استخدام الجيس الزراعي - استخدام

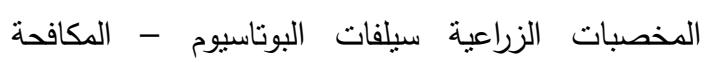
المنكاملة - حصاد القمح بالنشيير - زراعة الاذرة بالسطارة - زراعة القمح بالسطارة - خدمة آلية قبل

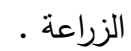
ونم القياس من خلال نطبيق التقنية من قبل الزراع

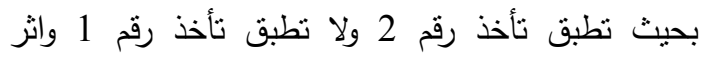

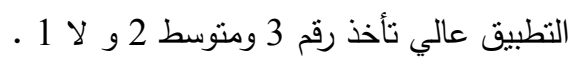
تحليل البيانات: تنَّ استخدام الإحصاء الوصفى والاستدلالى مثلى لتل (النسب المئوية والتوزيع التكرارى وبعض مؤشرات التحليل الإحصائى منل المتوسط الحسابى والانحراف المعيارى

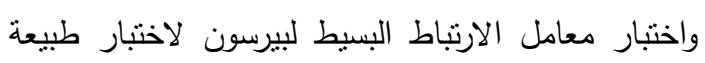

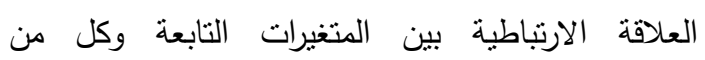
المتغيرات المستقلة والتحليل الانحدارى المتعدد والمتدرج الصاعد Step-wise multiple regression analysis وذلك لتحديد الإسهام النسبى لكل من المتغيرات المستقلة فى تفسير التباين الحادث فى المتغير التابع).

\section{نتائج البحث ومناقشاتها}

يتتاول هذا الجزء النتائج الخاصة بالزراع والاتجاه نحو

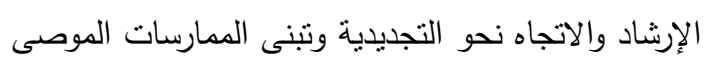
بها فى محصول القمح والذرة والبطاطس والفاصوليا. ودرجة التجديدية للزراع.

لاختبار صحة الفرض النظرى نم صياغة الفرض

الإحصائى التالى، لا توجد علاقة معنوية بين درجة تتفيذ

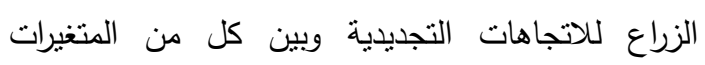

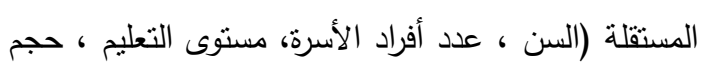

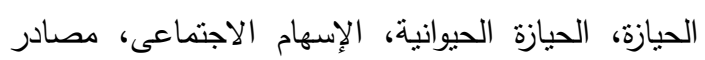

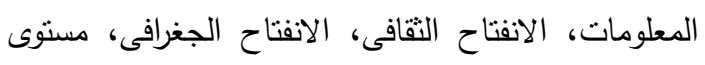
المعيشة، الاتجاه نحو الإرشاد). ولاختبار صحة هذا الفرض تم استخدام معامل الارتباط البسيط ونموذج التحليل الاتحدارى المتعدد 
التالية (السن- عدد أفراد الأسرة - الحبازة الحيوانية -

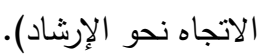

لاختبار صحة الفرض النظرى تم صباغة الفرض الإحصائى التالى، لا توجد علاقة معنوية بين درجة تجديدية الزراع وبين كل من المتغيرات المستقلة (السن، عدد أفراد الأسرة، مستوى التعليم ، حجم الحيازة، الحيازة

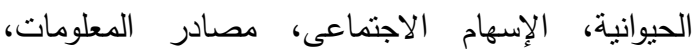

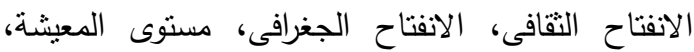

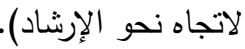

الانحدار، اتضح أن نسبة إمكانية رفض الفرض الإحصائى فيما ينعلق بالعلاقة بين درجة تتفيذ الزراع للاتجاهات التجديدية وبين المتغيرات المستقلة الددروسة مصادر المعلومات، الانفتاح الثقافى، ومستوى التعليم والإسهام الاجتماعى والانفتاح الجغرافى. وبالتالى يمكن قبول الفرض البديل بالنسبة لهذه المتغيرات في حين تم قبول الفرد الإحصائي في المتغيرات التالية فى حين نم قبول الفرض الإحصائى فى الأجزاء

جدول رقم (1): معامل الارتباط البسيط بين الاتجاهات التجديدية وبين المتغيرات المستقلة المدروسة.

\begin{tabular}{|c|c|}
\hline معامل الارتباط البسيط الخاص بالاتجاهات التجديدية & المتغيرات المستقلة \\
\hline 0.68 & 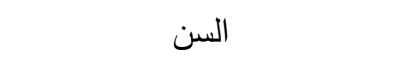 \\
\hline $0.17-$ & عدد أفراد الأسرة \\
\hline ** 0.446 & مستوى التعليم \\
\hline * 0.104 & 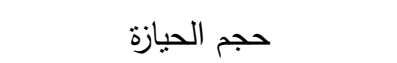 \\
\hline 0.0740 & الحيازة الحيوانية \\
\hline **0.434 & الإسهام الاجتماعى \\
\hline ** 0.610 & الاستفادة من مصادر المعلومات \\
\hline ** 0.598 & الانفتاح الثقافى \\
\hline ** 0.223 & الانفتاح الجغرافى \\
\hline * 0.210 & 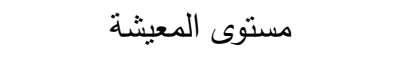 \\
\hline 0.80 & الاتجاه نحو الإرشاد \\
\hline
\end{tabular}

جدول رقم (2): نتائج تحليل الانحار المتعدد بين الاتجاهات التجديدية ويين المتغيرات المستقلة

\begin{tabular}{|c|c|c|c|c|c|c|}
\hline$F$ & للتباين اللمتنغير & للتباين اللتنتغير اكمية & التحديد معامل ${ }^{2}$ & $\begin{array}{c}\text { قيمة معامل الارنباط } \\
\text { R }\end{array}$ & 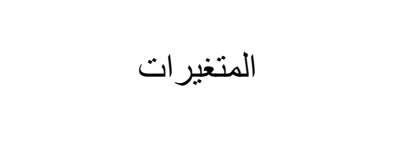 & $\begin{array}{l}\bar{y} \\
\bar{y}\end{array}$ \\
\hline ** 65.278 & 19.9 & 19.9 & 0.199 & 0.445 & مستوى التعليم & 1 \\
\hline ** 81.816 & 18.5 & 38.4 & 0.384 & 0.615 & الانفتاح الجغر افى & 2 \\
\hline ** 59.520 & 2.2 & 40.6 & 0.406 & 0.635 & الاستفادة من مصادر المعلومات & 3 \\
\hline
\end{tabular}




\section{Khairy, et al.,}

تجديدية الزراع، أى أنه بزيادة السن وبزيادة الوحدة الحيوانية لدى المبحوثين تقل درجة تجديدية الزراع المبحوثين. بينما اتضح عدم وجود علاقة ارتباطية معنوية فى أى اتجاه على مستوى 0.05 بين الدرجات المعبرة عن توجهات تجديدية المبحوثين وبين المتغيرات المستقلة التالية: الحالة الزوجية وعدد أفراد الأسرة والاتجاه نحو الإرشاد الزراعى، والانفتاح الجغرافى وحجم الحيازة الزراعية. ويتضح من النتائج ضرورة تشجيع صغار السن على تبنى المزارعين للتجديد وتتجيع الريفيين على التعليم والإسهام الاجتماعى ومصادر المعلومات عند تخطيط وتتفيذ البرامج المتعلقة بالحديث فى الزراعة المصرية. أوضحت نتائج بجدول رقم (4) الدراسة أن نموذج الانحدار المتعدد معنوى عند مستوى 0.01كما أن النموذج يفسر 35,9\% من التباين الكلى لارجة التجديدية لصغار الزراع حيث بلغت فيمة (F) المحسوبة 36,6 عند درجة معنوية 0,01 وهذا يعنى وجود ثلاث متغيرات مؤثرة على درجه الزراع للتجديد مرتبة ترنيبًا تتازليًا 25,6 يرجع إلى الإسهام الاجتماعى و 8,7 يرجع لمصادر المعلومات و 1,6 يرجع إلى مستوى المعيشة.
وللتحقق من صحة هذا الفرض تم استخدام معامل الارتباط البسيط و نموذج التحليل الانحدارى المتعدد الصاعد وأظهر التحليل الإحصائى باستخدام معامل الارتباط البسيط الموضحة بالجدول رقم (3) أن هناك الك علاقة ارتباطية موجبة معنوية على مستوى 0,01 وبين الدرجات المعبرة عن درجة تجديدية الزراع المبحوثين وبين كل من المتغيرات المستقلة التالية مرنبة ترتيبًا تتازليًا لعينة

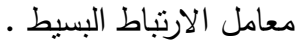
مستوى التعليم (0.564) والإسهام الإنيطئ (0.338) ومصادر المعلومات (0.314) ومستوى المعيشة 10.462 والانفتاح الجغرافى 0.338 • وتعنى تللك النتائج أنه بزيادة كل من تللك المتغيرات الخامسة المذكورة تزيد توجهات تجديدية المبحوثين بينما اتضح أن هناك علاقة ارتباطية عكسية معنوية 0.01 من الدرجات المعبرة عن درجة تجديدية الزراع المبحوثين وبين كل من المتغيرات التالية مرتبة تتازليًا وفقًا لقيمة معامل

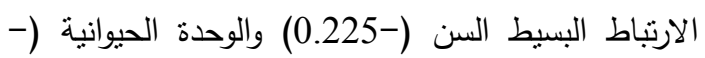
$\cdot(0.204$ وهذه النتائج الارتباطية العكسية تعنى أنه بزبادة السن بزيادة الوحدة الحيوانية للمبحوثين وتقل الدرجة المعبرة عن

جدول رقم (3): معامل الارتباط البسيط بين التوجهات التجديدية وبين المتغيرات المستقلة المدروسة

\begin{tabular}{|c|c|}
\hline معامل الارنباط البسيط الخاص التوجهات التجديدية & المتغيرات المسنقلة \\
\hline$* * 0.225$ & السن السن \\
\hline $0.084-$ & عدد أفراد الأسرة \\
\hline$* * 0.564$ & مستوى التعليم \\
\hline 0.050 & 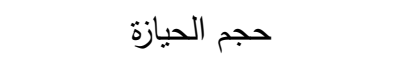 \\
\hline$* * 0.204$ & الحيازة الحيوانية \\
\hline$* * 0.506$ & الإسهام الاجتماعى \\
\hline$* * 0,314$ & الاستفادة من مصادر المعلومات \\
\hline 0.052 & 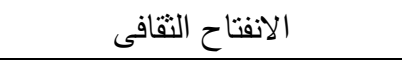 \\
\hline$* * 0.338$ & 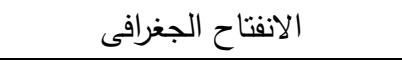 \\
\hline$* * 0.462$ & 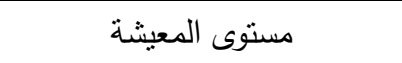 \\
\hline 0.70 & الاتجاه نحو الإرشّاد \\
\hline
\end{tabular}


Khairy, et al.,

جدول رقم (4): نتائج تحليل الانحدار المتعدد بين التوجهات التجديدية وبين المتغيرات المستقلة المدروسة.

\begin{tabular}{|c|c|c|c|c|c|}
\hline $\mathrm{F}$ & $\begin{array}{c}\text { \% التراكمية للتباين } \\
\text { الحادث في المتغير } \\
\text { التابع }\end{array}$ & $\begin{array}{c}\text { \% التراكمية للنتاين } \\
\text { المفسر للمتغير } \\
\text { التابع }\end{array}$ & $\begin{array}{l}\text { قيمة معامل }{ }^{2} \text { التحديد }\end{array}$ & قالميمة الارتباط & خطوات التحليل \\
\hline$* * 68.013$ & 25,6 & 25,6 & 0.256 & 0.506 & الإسهام الاجتماعى \\
\hline$* * 51.526$ & 8,7 & 34,3 & 0.343 & 0.586 & مصادر المعلومات \\
\hline$* * 36.619$ & 1,6 & 35,9 & 0.359 & 0.599 & مستوى المعيشة \\
\hline
\end{tabular}

بعمل ندوات تعليمية وتثقيفية عن المستحدثات

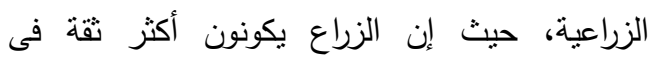

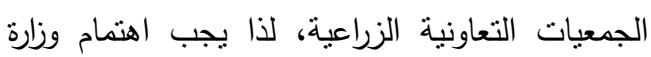
الزراعة بدور الجعيات التعاونية الزراعية فى خدمة الزارع وتوفير معظم مستلزمات الإنتاج الزراعية.

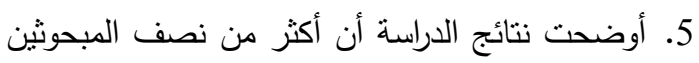

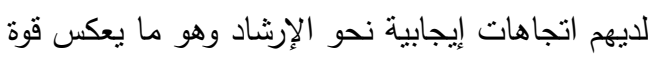

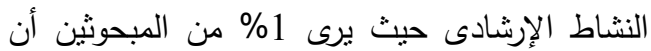
الإرشاد لا يساعدهم، فى حين يرى 25\% من الإناسي

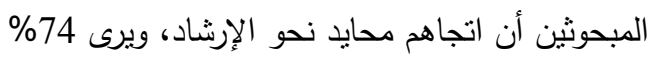

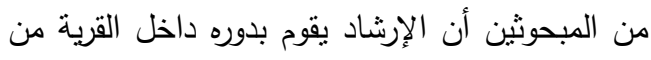

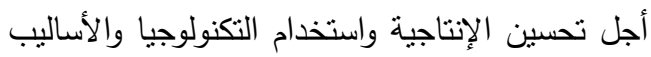
الزراعية الحديثة النى تساعدهم على زيادة الإنتاج، وبالتالى توصى الدراسة بضرورة توفير الإمكانيات

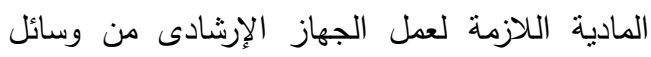
انتقال ومعينات إرشادية وأماكن الاجتماعات الإرشادية لإنمادية من وساتل وتجهيزها بالأجهزة المتطورة لمواكبة النطور الحادث فى القطاع الزراعى.

6. أوضحت نتائج الدراسة أن 60\% من المباع البحوثين لديهم

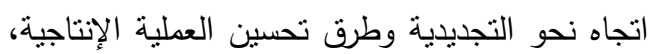

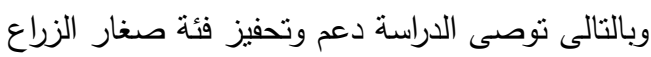
واهتمام الإرشاد بنلك الفئة ودعمهم على استخدام الأساليب الحديثة فى الزراعة.

أهمية إثراف القادة المحليين فى الأنشطة الزراعية

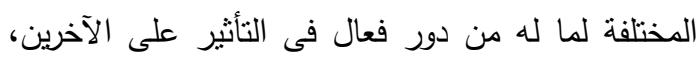




\section{Khairy, et al.,}

8. السيد محمد الحسيني وآخرون ، دراسات في التتمية الاجتماعية ، دار المعارف مصر، 1987م 9. صالح ، صبري مصطفي محمد ( 1976 ) " دراسة اتجاهات القيادات التعاونية الزراعية الريفية نحو بعض المطبوعات الارشادية الزراعية في مركز

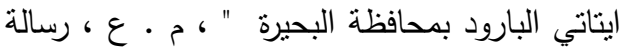
ماجستير ، كلية الزراعة جامعة الاسكندرية . 10. صالح ، صبري مصطفي محمد ( 1997 ) " مرجع

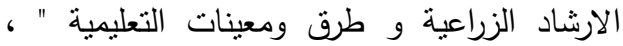
منشورات جامعة عمر المختار ، البيضاء

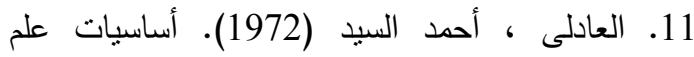

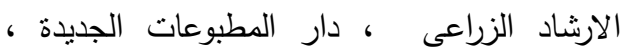
الاسكندرية . 12. عازر ، كرم يوسف (2004). معارف واتجاهات زراع القطن نحو برنامج المكافحة المتكاملة لآفات القطن في محافظة المنوفية ، رسالة دكتوراه ، كلية الزراعة بالفيوم ، جامعة القاهرة. 13. عبدالمقصود ، بهجت محمد (1988 ) الارشاد الزراعي ، المركز العلمي للبحوث والدراسات. 14. عثمان، ايمان ماهر محمود (2009). تبنى المرأة الريفية للممارسات البيئية بمحافظة المنوفية ، رسالة ماجستير ، كلية الزراعة ، جامعة المنوفية ، مصر.

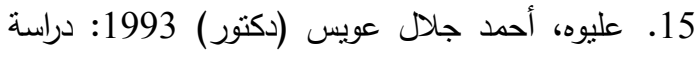
تحليلية لمدى مشاركة المزارعين فى الأنشطة الإرشادية الزراعية وبعض العوامل المرتبطة بها فى الى العئه محافظة الفيوم، مجلة الفيوم للبحوث والتتمية الزراعية، كلية الزراعة بالفيوم، جامعة القاهرة، مجلد

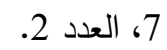

16. عمر وآخرون (1976) ، الارشاد الزراعي طرق و برمجة ، دار النهضة العلمية ، القاهرة 17. قتنطة عبدالحليم عباس (2012 ) الارشاد الزراعي رؤية جديدة كلية الزراعة جامعة القاهرة .

$$
\text { 18. محمد (1995 عن رضوان) }
$$

19. المليجى، حازم محمد وحمدى السيد رافع (1998): دراسة مقارنة لمستوى معرفة الزراع للتوصيات
ونقل التوصيات الإرشادية والتكنولوجيا الجديدة فى

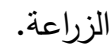

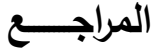

\section{أولا: المراجع العربية}

1. درويش، زين العابدين وآخرون (دكاترة) 1993: علم

النفس الاجتماعى، أسسه وتطبيقاته، مطابع زمزم،

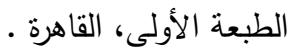
2. زهران، يحيى على وآخرون (دكاترة) 2002: الدليل

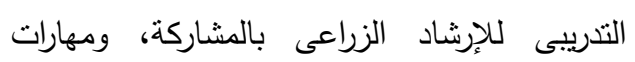
التيسير، مشروع المكافحة المتكاملة للآفات، مديرية الزراعة بالفيوم، وزارة الزراعة. 3. سكر، عبد العاطى عبده محمد (1996) دراسة اتجاهات الزراع نحو الحملة القومية للإرشاد الزراعى العي للقمح فى بعض قرى مركز كوم حماده محافظة البحيرة، رسالة ماجستير، كلية الزراعة، جامعة

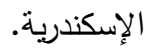
4. سلامه، فؤاد عبد اللطيف (2001). تحليل مسارى الإن

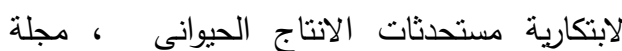
المنوفية للبحوث الزراعية ، مصر ، مجلد 26 ،

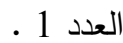
5. سلامه، فؤاد عبد اللطيف (2001). تحليل مسارى

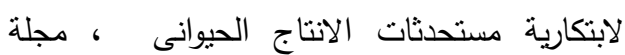
المنوفية للبحوث الزراعية ، مصر ، مجلد 26 ، العدد 1 . الع 6. سويف، مصطفى (دكتور) 1970: مقدمة فى علم النفس الاجتماعى، مكتبة النهضة المصرية، الطبعة

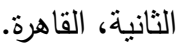
7. سويلم ، محمد على ، محمد أحمد عبد القادر ، القانه، القرة محمد عبدة مرسى ( 1992). دور المرشد الزراعى فى تتفيذ الريفين للممارسات المزرعية الجديدة ، نشرة بحثية رقم 95 ، معهد بحوث الارشاد الزراعى الإنى والتتمية الريفية ، مركز البحوث الزراعية ، وزارة

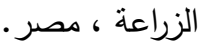




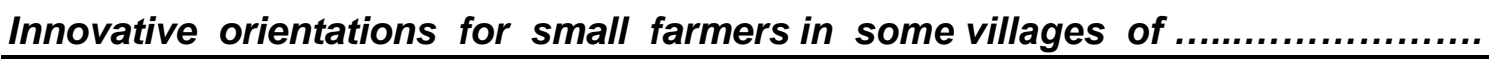

اتجاهات العاملين الزراعيين نحو العمل الإرشادى

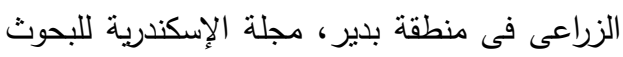

الزراعية، المجلد (4) العدد الثالث.

\section{ثانيًا: المراجع الأجنبية}

1. Kreach, D. and R.S. Curtchfield (1948). "Theory and problem of social psychology" Inc- New York.

2. Mouly, G.J. (1982). Psychology for Teaching" Boston: Ailn and Bacon, inc.

3. Rogers, E. M. (1965). Diffusion of Innovation, the free press, New York, USA.

https://www.google.com.eg/search?biw=128 $0 \&$ bih $=865 \& q$

4. www.Agricultureegypt.com/NewsDetail.

$$
\begin{aligned}
& \text { والممارسات الخاصة بزراعة وإنتاج الموز بمنقطة } \\
& \text { الاسنصلاح الجديد وأخرى قديمة بمحافظة المنوفية، }
\end{aligned}
$$

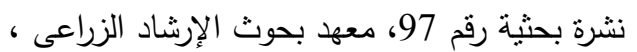

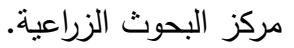

$$
\begin{aligned}
& \text { 20. منسى، محمود عبد الحليم وآخرون (دكاترة) 1994: } \\
& \text { علم النفس الاجتماعى، دار المعرفة الجامعية، } \\
& \text { الإسكندرية. } \\
& \text { 21. نشواتى، عبد الهجيد (دكتور) 1987: علم النفس الإنكانه } \\
& \text { التربوى، دار الفرقان للنشر والطبع، الطبعة الثانية، } \\
& \text { مؤسسة الرسالة، بيروت. } \\
& \text { 22. النصار، صالح نصار وآخرون (دكانرة) 1996: } \\
& \text { دراسة تحليلية لبعض العوامل المؤثرة على مستوى }
\end{aligned}
$$


Khairy, et al.,

\title{
INNOVATIVE ORIENTATIONS FOR SMALL FARMERS IN SOME VILLAGES OF MENOFIA GOVERNORATE
}

\author{
Doria M. Khairy, A. R. Henedy, E. S. A. Shahen and Amal Y. Mahmoud \\ Dept. of Agric. Ext. and Rural Sociology, College of Agric., Menoufia University
}

\begin{abstract}
The study aimed to identify the economic، social and communicative agricultural properties, and to identify the level of adoption of the farmers for the recommendations of the following crops (wheat - corn - potato - beans), determine the farmers' attitudes towards these new recommendations in the study, determine the degree of regenerative and identify associated and achieved trends regenerative factors. The data were collected during the month of February and March 2016 from the villages (Al Khadra \& Bai El Arab) which belong to (Bagour Provence) and the villages of (Kafr Aoun and Kafr Mansour) which belong to (Ashmun Provence).

This procedure is done by using personal questionnaire against a random sample of regular strength (200) Researched by holders of tenure records Agricultural Cooperative Society. It was used descriptive statistics and analytical data analysis.

\section{Results}

1. Results of the study showed that more than half of the respondents have positive attitudes towards counseling.

2. The results showed that $60 \%$ of respondents have a trend towards regenerative agriculture and ways to improve the production process.

3. The results of the study showed that there are three variants of the same correlation independent variables: the social contribution and sources of information and the quality of life contributes to a significant contribution at a level of 0.01 in the interpretation of contrast kidneys to the point of implementation of small-scale farmers trends innovative contribution by $16.33 \%$.

4. The results show that there are three variables have contributed to a significant variation in the interpretation of macro-trends for innovative small farmers, namely, (the level of education cultural openness - information sources) with a rate of contribution of $40.6 \%$.
\end{abstract}

Key words: Innovative, regenerative, small farmers, attitudes. 